\title{
Editorial
}

\section{Open access: a revolution in scientific publishing}

\author{
Bhaven C. Kataria*
}

Department of Pharmacology, GMERS Medical College, Sola, Ahmedabad, Gujarat, India

\author{
*Correspondence: \\ Dr. Bhaven C. Kataria, \\ E-mail: drbkataria@gmail.com
}

(C) 2014 Kataria BC. This is an open-access article distributed under the terms of the Creative Commons Attribution Non-Commercial License, which permits unrestricted non-commercial use, distribution, and reproduction in any medium, provided the original work is properly cited.

The way that research is communicated is changing rapidly. The internet has made it possible, a revolutionary way of providing access to the articles published in scholarly journals. The rising cost of subscription of scholarly journals, has seriously hampered the ability of libraries, research centers, and researchers to acquire publications necessary for research and knowledge enhancement. Open access publishing provides a way for addressing this challenge by offering a very cost-effective alternative to the traditional publishing model. Before the mid-1990s, most of the journals were available only on paper and accessible by subscription. By the end of the $20^{\text {th }}$ century, most journals had moved their content to online platforms.

Open access (OA) in simple meaning refers to unrestricted online access to the articles published in scholarly journals. There are two distinct ways articulated in the Budapest Open Access Initiative: (1) Articles directly provided by the journal publisher (also called "gold OA"), or (2) Indirectly by author self-archiving and/or being uploaded and made freely available somewhere else on the web (also called "green OA"). Green open access requires the author to deposit a peerreviewed manuscript in an institutional or central repository such as PubMed Central. Both options increase the potential readership of any article.

The open-access policy has found strong supporters in developing and developed countries. Currently Directory of Open Access Journals (DOAJ), one of the largest databases for open access journals, includes 9722 journals, published from 134 countries. $^{2}$ The UK government gives support for open-access publishing. The Research Councils UK, a coordinator for research funding, highlighted the intention to mandate publishing in journals with open access. ${ }^{3}$ The Lancet journals, also welcome open access policy, operating alongside the traditional subscription model. ${ }^{4}$ There are many organizations, such as SPARC (the Scholarly Publishing and Academic Resources Institute) and the Open Society Foundations, that work for progress in Open Access. 5,6

PLOS (Public Library of Science) as a pioneer of open access publishing has helped to liberate tens of thousands of research articles. PLOS believes that there is much to be gained from assessing research articles on their own merits rather than on the basis of the journal (and its impact factor) where the work happens to be published. ${ }^{7}$ Many other reputed publishers have joined in the new wave of open access publishing. The BMJ Group launched the BMJ Open journal in 2011. Since then there has been rapid growth of BMJ Open. These successful examples highlight the acceptability of the new publishing model. There are growing number of organizations and publishers mandating open access policy. ${ }^{8,9}$ OpenDOAR has over 2600 listing. ${ }^{9}$ The Centre for Research Communications (CRC) at the University of Nottingham works nationally and globally with researchers, funders, institutions and publishers, on challenges and exciting opportunities in opening access to research. The CRC houses a portfolio of open access projects, services and initiatives. These include the SHERPA Services for Open Access - RoMEO, JULIET, FACT and OpenDOAR and the University contribution to the European and international projects MedOANet, OpenAIRE and Dart-Europe. PubMed Central is a repository of peer-reviewed and published manuscripts designed to provide the public with access to the research supported by their tax dollars. ${ }^{11}$

In an attempt to build a gradual transition path between the traditional subscription journals and open access 
several major publishers such as Springer, Wiley, Elsevier, Oxford University Press and Bentham Science have started offering so-called "hybrid" journals. These are traditional closed access subscription journals, which offer individual authors the possibility to open up their articles for free access from day one, against a payment. ${ }^{12}$ Though the hybrid model seems advantageous for publishers and authors, it may lead to unethical prioritization of paid open-access papers. ${ }^{13}$ The open access has also changed webometric and citation figures for most scholarly journals by attracting attention of the readers to the easily accessible online contents. The Article-Level Metrics can be applied in a transparent manner to individual articles to accurately assess their importance and impact.

Funders invest in research in order to accelerate the pace of scientific discovery, encourage innovation, enrich education, and stimulate the economy - to improve the public good. They recognize that broad access to the results of research is an essential component of the research process itself. Research advances only through sharing of results, and the value of an investment in research is only maximized through wide use of its results. $^{14}$

In conclusion, digital content delivery has, within a relatively short time-span, shifted the landscape of scientific publishing considerably and opened up the alternative ways of distributing scientific literature. Authors and publishers are increasingly embracing the open access model of scientific publishing. However, secure research funding and more transparent financing of the open-access model may add to sustainability of future scientific publishing.

\section{REFERENCES}

1. Budapest Open Access Initiative. Available at http://www.budapestopenaccessinitiative.org/boai10-recommendations. Accessed 19 April 2014.

2. Directory of Open Access Journals (DOAJ). Available at http://doaj.org. Accessed 28 April 2014.
3. Hawkes N. UK government comes down in favour of making all publicly funded research "open access". BMJ. 2012;345:e4878.

4. The Lancet journals welcome a new open access policy. Lancet. 2013;381:1166-7.

5. The Scholarly Publishing and Academic Resources Coalition (SPARC). Available at http://www.sparc.arl.org/. Accessed 28 April 2014.

6. Open Society Foundations. Available at http://www.opensocietyfoundations.org/ Accessed 28 April 2014.

7. PLOS (Public Library of Science). Available at http://www.plos.org/about/plos/. Accessed 28 April 2014.

8. ROARMAP. Registry of Open Access Repositories Mandatory Archiving Policies. Available at http://roarmap.eprints.org/. Accessed 25 April 2014.

9. OpenDOAR. The Directory of Open Access Repositories. Available at http://www.opendoar.org/index.html. Accessed 29 April 2014.

10. Centre for Research Communications. Available at http://crc.nottingham.ac.uk. Accessed 28 April 2014.

11. Frank M. Open but not free--publishing in the 21st century. N Engl J Med. 2013 Feb 28;368(9):787-9.

12. Björk Bo-Christer. 2012. The Hybrid Model for Open Access Publication of Scholarly Articles - a Failed Experiment? Available at http://www.openaccesspublishing.org/hybrid/hybrid .pdf. Accessed 20 April 2014.

13. Salem DN, Boumil MM. Conflict of interest in open-access publishing. $\mathrm{N}$ Engl J Med. 2013;369:491.

14. SPARC. Why open access? Available at http://www.sparc.arl.org/resources/openaccess/why-oa. Accessed 20 April 2014.

DOI: $10.5455 / 2349-3933 . i j a m 20140501$

Cite this article as: Kataria BC. Open access: a revolution in scientific publishing. Int J Adv Med $2014 ; 1: 1-2$ 